\title{
TRANGÊNEROS: A VITÓRIA NO JULGAMENTO DA AÇÃO DIRETA DE INCONSTITUCIONALIDADE № 4275
}

\author{
Rafaela Parpinéli de Oliveira, Carolina Beduschi Klébis; Fábio Ferreira Morong. \\ Universidade do Oeste Paulista, Curso de Direito, Presidente Prudente, SP. E-mail: rafaceciliaoliveira@hotmail.com, \\ carolbeduschi@hotmail.com e fabiomorong@hotmail.com.
}

\section{RESUMO}

O presente artigo objetiva realizar uma breve análise do julgamento da Ação Direta de Inconstitucionalidade no 4275 (ADI) realizado pelo Supremo Tribunal Federal, ajuizada pela Procuradoria Geral da República,bem como dispor sobre as mudanças trazidas pela mesma.mo método aplicado foi o dedutivo legal, baseado na interpretação da legislação, julgados, portarias, provimentos e em pareceres emitidos por órgãos competentes.Com efeito, o assunto é relevante haja vista que as transformações trazidas a partir desta decisão da suprema Corte,geram mais conforto às pessoas que conviviam, até poucos meses atrás, com a lentidão do Judiciário e as conseqüências vexatórias a que eram expostas devido à suas situações de fato contradizerem às de direito.Conclui-se que a decisão do STF no julgamento da ADI no 4275 possui grande relevância, pois é um marco importante diante da omissão do Poder Legislativo em legitimar questões primordiais para uma parcela significativa da população, que vive na marginalidade da sociedade. Palavras-chave: Ação Direta de Incostitucionalidade. Supremo Tribunal Federal. Trasngênero. Prenome. Gênero.

\section{TRANSGENDER: THE VICTORY IN JUDGMENT OF THE DIRECT ACTION OF UNCONSTITUTIONALITY № 4275}

\begin{abstract}
The present article aims to make a brief analysis of the judgment of the Direct Action of Unconstitutionality No. 4275 (ADI) conducted by the Federal Supreme Court, filed by the Attorney General's Office, as well as dispose of the changes brought by it. The method applied was the legal deductive, based on the interpretation of legislation, judgments, ordinances, appeals and opinions issued by competent bodies. In fact, the matter is relevant since the changes brought by this decision of the Supreme Court, generate more comfort to people who lived, even a few months ago, with the slowness of the Judiciary and the vexatious consequences to which they were exposed because of their situations of fact contradict to those of right. It is concluded that the decision of the STF in the judgment of ADI $n=4275$ has great relevance, since it is an important landmark due to the omission of the Legislature to legitimize issues that are of prime importance for a significant portion of the population living in the marginality of society.
\end{abstract}

Keywords: Direct Action on Inconstitutionality. Federal Court of Justice. Trasng. Firstname. Genre. 


\section{INTRODUÇÃO}

Em 01ㅇ de março de 2018, no julgamento da Ação Direta de Inconstitucionalidade no 4275 (ADI), o plenário do Supremo Tribunal Federal (STF), por maioria de votos, emitiu entendimento favorável à referida ADI,ajuizada pela Procuradoria Geral da República (PGR), que solicitava que o artigo 58 da Lei de Registros Públicos (Lei no 6.015/73) fosse interpretado conforme o Pacto de San José da Costa Rica e a Constituição Federal. O que a PGR buscava era a possibilidade de alteração de prenome e gênero diretamente no Registro Civil, sem a necessidade de uma prévia aquiescência judicial.

As considerações a respeito deste julgado trazem, ainda, de forma resumida, os votos, favoráveis e contrários dos ministros da Suprema Corte, apontando os pontos em que se assemelham e os que se destoam a respeito do assunto.Com efeito, ante as mudanças expressivas trazidas pela citada decisão, consequentemente surgem situações problemáticas, pois a partir de um julgamento têm-se alterações que refletem em diversos outros âmbitos, afetando, inclusive, terceiros, conforme será analisado mais adiante.

Por fim, o presente trabalho tem como objetivo realizar um breve crivo sobre o veredicto que fez com que o Estado deixasse de limitar ou obstar o direito à identidade de gênero, dando um passo extraordinário na luta contra a discriminação, sem esquecer-se do caráter pedagógico desta decisão, que pretende conscientizar à população, encaminhando-a para o desejo de um futuro onde o preconceito poderá ser apenas uma palavra.

\section{METODOLOGIA}

O presente trabalho empregou pesquisas à legislação nacional, sites de órgãos Judiciários e Administrativos, pareceres, votos, portarias, provimentos e opiniões relevantes na matéria objeto de estudo, utilizando o método dedutivo para estruturar as informações obtidas.

\section{COMPREENSÃO DO TERMO “TRANSGÊNERO”}

Quando uma mulher engravida, após um período, sabendo-se que a gravidez corre bem, a primeira pergunta que surge é: é menina ou menino? Alguns pais possuem certa preferência pelo sexo do bebê a caminho, no entanto, esse conceito sexual é apenas médico, baseado em questões hormonais e na aparência dos órgãos genitais. De outro lado, esse critério está longe de definir todas as questões que decorrem dessa classificação tão simplista.

O termo "transgênero" ou "trans" se refere a uma pessoa cuja identidade de gênero - o sentimento psicologicamente consolidado de ser um homem, uma mulher, ou nenhuma das duas categorias - não corresponde ao seu sexo de nascimento, biológico. (PRESSE, 2016).

Esta definição inclui as pessoas que se submeteram pela cirurgia de redefinição sexual, as que só receberam um tratamento hormonal e também aquelas que não passaram por nenhum desses procedimentos, mas se identificam e vivem em desacordo com seu sexo biológico, registrado em suas certidões de nascimento. Importante ressaltar que a identidade de gênero não se confunde com a orientação sexual. Uma mulher ou homem transgênero pode ter qualquer orientação sexual: homossexual, heterossexual ou bissexual. (PRESSE, 2016).

As identidades de gênero abrangem uma complexidade humana imensa. Simone de Beauvoir, que foi uma das mais importantes feministas da História, em sua obra "O Segundo Sexo" sustenta que "Não se nasce mulher, torna-se mulher" (apud SENKEVICS, 2017). De fato, o respaldo para defender que não se pode considerar que mulher é aquele ser humano que nasceu com um útero, o gênero tem muito mais afinidade com a cultura, atitudes, e como a pessoa se sente e se enxerga. 


\section{DO JULGAMENTO DA AÇÃO DIRETA DE INCONSTITUCIONALIDADE № 4275}

Primeiramente, se faz necessário entender o conceito de Ação Direta de Inconstitucionalidade (ADI), que segundo MORAES (2016, p.781) tem por finalidade "retirar do ordenamento jurídico lei ou ato normativo incompatível com a ordem constitucional."

Conforme ensina Alexandre de Moraes (2016, p.792):

O julgamento da ação direta de inconstitucionalidade será realizado pelo Plenário do Supremo Tribunal Federal, em respeito ao art.97 da Constituição Federal, exigindo-se quorum mínimo de oito Ministros, para instalação da sessão que, entendendo tratar-se de lei ou ato normativo constitucional, fará essa declaração expressamente, julgando improcedente a ação direta de inconstitucionalidade; ficando, destarte, vedada a possibilidade de ação rescisória deste julgado.

Como no ordenamento brasileiro há uma supremacia das normas constitucionais, ao interpretar leis e atos normativos editados pelo poder público, deve-se procurar dar um sentido à norma, que se adéqüe à Carta Magna. (MORAES, 2016).

A ADI no 4275 ajuizada pela Procuradoria Geral da República em 2009 solicitava que o artigo 58 da Lei de Registros Públicos fosse interpretado em conformidade com o Pacto de San José da Costa Rica e a nossa Constituição Federal de 1988. O citado artigo 58 da Lei 6.015/1973, dispõe sobre o prenome e em seu parágrafo único admite a substituição em caso de "fundada coação ou ameaça decorrente da colaboração com a apuração de crime, por determinação, em sentença, de juiz competente, ouvido o Ministério Público." (BRASIL, 1973).

A ADIvisava incluir ao artigo 58 da Lei de Registros Públicosa possibilidade de alteração do prenome para aquelas pessoas que não se identificam com o sexo biológico constante no registro de nascimento e, consequentemente com seu prenome.

O Supremo Tribunal Federal reconheceu o pedido ajuizado pela PGR, garantindo que os transgêneros, independente de cirurgia de redefinição sexual, ou da realização de tratamentos hormonais, possuem o direito à modificação de prenome e sexo, sem a necessidade de autorização judicial, diretamente nos Cartórios de Registro Civil. (CARTÓRIO..., 2018).

Votaram pela procedência do pedido, os ministros Edson Fachin, Luiz Roberto Barroso, Rosa Weber, Luiz Fux, Celso de Mello e a presidente do Supremo, ministra Cármen Lúcia. Foram vencidos, o Relator Marco Aurélio e os ministros Alexandre de Moraes, Ricardo Lewandowski e Gilmar Mendes. Estava impedido o ministro Dias Toffoli. (SUPREMO TRIBUNAL FEDERAL (STF), 2018).

A decisão do STF foi recebida com alegria. Na opinião da presidente da Articulação Nacional De Travestis E Transexuais (Antra), Keila Simpson (2018) (apud Transgêneros..., 2018, p. 17), o STF fez o papel do legislador atendendo aos anseios dessa parcela da população, além de garantir a dignidade de se ter um nome em consonância com o gênero que determinada pessoa se identifica.

Diante do julgado do STF, foi possível observar que duas correntes se formaram. Uma encabeçada pelo Relator, ministro Marco Aurélio, que restou vencida com cinco votos. Outra, conduzida pelo ministro Ricardo Lewandowski, foi vencedora com seis votos. Ambas posições concordaram com a possibilidade de mudança do prenome e do gênero e também admitiram não ser necessária a cirurgia de redefinição sexual para tal procedimento. Divergiram, no entanto, quanto aos requisitos que julgam necessários para realização do pedido e sobre a obrigatoriedade dele ser feito pela via judicial. (KUMPEL; VIANA, 2018, p. 28). 


\section{DAS MUDANÇAS TRAZIDAS PELO JULGAMENTO PROCEDENTE DA ADI № 4275 E O PROVIMENTO № 73/2018}

Além de por um fim em questões de opressão, o julgamento do STF também foi visto como um marco na luta contra a violência e o preconceito que afligem os transgêneros no Brasil.(Transgêneros..., 2018, p. 16).

Simples ações como ir ao médico, abrir uma conta em um comércio ou ir a uma entrevista de emprego, passarão a ser coisas normais - como já deveriam ser - para pessoas que não se identificam com seu gênero registrado na certidão de nascimento. Isso porque, é um grande constrangimento apresentar documentos que não condizem com seu nome social, nem com sua aparência física.

É certo que a decisão possui uma abrangência nacional e também internacional, visto que, com isso, o Brasil sai na frente de muitos países vizinhos na luta pela igualdade de direitos (GORISCH, 2018,não paginado)

Por sua vez, o 9o Oficio de Registro Civil de Campo Grande (MS) foi pioneiro em fazer a mudança de prenome e gênero sem prévia autorização judicial. Com isso nota-se que o processo de extrajudicialização está avançando cada vez mais no país, o que é motivo de comemoração para os operadores do Direito. (CARTÓRIO..., 2018, p. 20).

O recente artigo publicado na Revista da Associação dos Registradores de Pessoas Naturais do Estado de São Paulo (ARPEN/SP), sob o título Cartórios realizam primeiros registros de mudança de nome e gênero (2018, p.20-21), explana o seguinte:

Em Santos, após a decisão do STF, o juiz corregedor Frederico dos Santos Messias, da 4a Vara Cível, editou, no dia 9 de março, uma portaria liberando as serventias da cidade a fazerem a retificação de nome e gênero dessa população sem precisar de decisão judicial. O magistrado editou a Portaria 01/2018, que determina que todo cidadão trans que tiver sido registrado em Santos poderá solicitar a alteração direto no cartório. Entretanto, ressalta que não haverá um esquecimento da vida pregressa da pessoa.

Denota-se que apenas a pessoa que requereu a modificação poderá solicitar uma $2^{a}$ via da certidão modificada em inteiro teor.

Alguns meses após o veredicto do Supremo, a Egrégia Corregedoria Nacional de Justiça regulamentou, no dia 29 de junho de 2018, o procedimento de alteração, em cartório, do prenome e sexo nos registros de nascimento e casamento de pessoas transgêneros.(CONSELHO NACIONAL DE JUSTIÇA (CNJ), 2018).

O Provimento no 73/2018 em seu artigo 10 explica sua finalidade, que é a mudança do prenome e gênero nos registros de nascimento e casamento de pessoas transgêneros, diretamente no Registro Civil. (BRASIL, 2018).

Em seu artigo 20 dispõe que "Toda pessoa maior de 18 anos completos habilitada à prática de todos os atos da vida civil poderá requerer ao ofício do RCPN a alteração e a averbação do prenome e do gênero, a fim de adequá-los à identidade autopercebida." (BRASIL, 2018).

Os parágrafos 1 e e 2 o do artigo acima transcrito dispõem, sobre a impossibilidade de supressão de sobrenome, com exceção de agnome familiar (filho, sobrinho, neto, júnior), uma vez que este tem a função de diferenciar membros de uma mesma família que possuem o mesmo nome (uma vez trocado o prenome não haverá mais essa necessidade). Importante lembrar que o contrário também é possível. (BRASIL, 2018).

$\mathrm{O}$ art. 2ㅇ ainda diz ser possível a realização deste procedimento em Ofício diverso daquele onde foi lavrado o assento de nascimento e, se for o caso, de casamento. Quando isso ocorrer, o registrador do cartório em questão encaminhará o procedimento ao cartório competente para que seja feita a devida averbação. (BRASIL, 2018). 


\section{DOS REQUISITOS EXIGIDOS PELO PROVIMENTO № 73/2018 DO CNJ}

A citada norma traz alguns requisitos a serem observados. O primeiro deles é o requisito subjetivo, que é caracterizado em razão do consenso em não haver a necessidade de cirurgias, tratamentos hormonais ou laudos médicos, todavia, é indispensável que a identidade de gênero com a qual a pessoa se identifica esteja, mesmo que minimamente, exteriorizada. (SOUZA, 2018).

Já o requisito objetivo pode ser assinalado pelos documentos exigidos pelo art. 60, incisos, do Provimento no 73/2018 do CNJ, que são: certidão de nascimento ou casamento se for o caso, atualizadas; cópia do RG, CPF, título de eleitor e comprovante de endereço; cópia da identificação civil nacional se for necessária; cópia de carteira de identidade social se preciso; certidão do distribuidor cível do local de residência dos últimos cinco anos (estadual/federal); certidão do distribuidor criminal do local de residência dos últimos cinco anos (estadual/federal); certidão de execução criminal do local de residência dos últimos cinco anos (estadual/federal); certidão dos tabelionatos de protestos do local de residência dos últimos cinco anos; certidão da Justiça Eleitoral do local de residência dos últimos cinco anos; certidão da Justiça do Trabalho do local de residência dos últimos cinco anos; certidão da Justiça Militar, a depender do caso. (BRASIL, 2018).

Todo o procedimento deve ficar arquivado na Serventia onde se desenrolou, sendo vedado constar na certidão de nascimento ou casamento qualquer averbação que viole o direito à intimidade, honra e vida privada da pessoa interessada. Devido a isso, a certidão em inteiro teor somente poderá ser emitida mediante requerimento da própria pessoa registrada ou por determinação judicial. (SOUZA, 2018).

\section{DAS CRÍTICAS À DECISÃO DO STF}

Para alguns, a decisão do STF no julgamento da ADI 4275 pode trazer algumas inseguranças nas relações com terceiros. Apontam hipóteses de induzimento a erro, como por exemplo, no caso de alguém contrair matrimônio com pessoa transgênero desconhecendo este fato. Supondo que isso acontece, sabe-se que é impossível a geração de filhos biológicos do casal, sendo o casamento, portanto, passível de anulação. (SOUZA, 2018).

Por sua vez, um fato que não ficou esclarecido está relacionado a relação à modificação no registro de nascimento dos filhos dessa pessoa que alterou o prenome e gênero. No caso de filhos menores entendemos que seria obrigatório, visto que é um direito do pai ou da mãe ter seu nome no registro dos filhos. Mas, pode-se indagar no sentido de que quando se tratar de filhos maiores, se esse filho recusara modificar o nome de algum dos genitores, alegando que viria a sofrer algum tipo de preconceito ou constrangimento, poderia retirar o nome de algum dos genitores? Por hora, essas questões deverão ser decididas pelo Poder Judiciário, o que vai contra a extrajudicialização pretendida na decisão do Supremo.

\section{CONCLUSÃO}

Através do presente artigo foi possível realizar uma breve análise geral a respeito do julgamento realizado pelo STF na ADI no 4275 e sobre o provimento 73/2018 da Corregedoria Nacional de Justiça.

Assim, levando-se em consideração o que foi estudado, é possível perceber quão significativa foi a decisão do Supremo, tirando milhares de pessoas da marginalidade e da exclusão social e, ainda, quando possibilitou que todo o procedimento seja realizado diretamente nas Serventias Extrajudiciais. Pode-se entender que este avanço, promovido por meio do Poder Judiciário, não supre o papel do legislador, que tem se omitido a respeito do tema, mas que provavelmente causou um incômodo neste. 


\section{REFERÊNCIAS}

BRASIL. Congresso Nacional. Lei de Registros Públicos. Lei n. 6.015 de 31 de dezembro de 1973. Dispõe sobre os Registros Públicos e dá outras providências. Disponível em:<http://www.planalto.gov.br/ccivil/leis/L6015.htm>. Acesso em: 11 jul. 2018;

BRASIL. Supremo Tribunal Federal. Ação Direta de Inconstitucionalidade no 4.275. Decisão Procedência da ADIN 4275 - Votos dos Ministros. Requerente: Procurador-Geral da República; Requerido: Presidente da República, Congresso Nacional. Brasília, DF, 01 março 2018. Brasília, DF, 01 março 2018.2 Disponível em: <http://www.stf.jus.br/portal/cms/verNoticiaDetalhe.asp?idConteudo=371085>. Acesso em: 11 jul. 2018;

BRASIL. Corregedoria Nacional de Justiça. Provimento n. 73, de 28 de junho de 2018. Dispõe sobre a averbação da alteração do prenome e do gênero nos assentos de nascimento e casamento de pessoa transgênero no Registro Civil das Pessoas Naturais. Diário de Justiça Eletrônico do CNJ Brasília, DF, 29 jun. de 2018. Disponível em:<https://www.conjur.com.br/dl/cnj-regulamentaalteracoes-nome-sexo.pdf>. Acesso em: 11 jul. 2018;

BRASIL. Supremo Tribunal Federal. Ação Direta de Inconstitucionalidade $n=4.275$. Medida liminar - Procedência da ADIN 4275 - Decisão final: Plenário, 10.3.2018. Requerente: Procurador-Geral da República; Requerido: Presidente da República, Congresso Nacional. Brasília, DF, 01 março 2018. Brasília, DF, 01 março $2018 . \quad$ Disponível em: <http://www.stf.jus.br/portal/peticaolnicial/verPeticaolnicial.asp?base=ADIN\&s1=4275\&processo $=4275>$. Acesso em: 10 jul. 2018;

CARTÓRIOS realizam primeiros registros de mudança de nome e gênero. ARPEN/SP, São Paulo, $n$. 181, p. 20-21, mar./abr. 2018.

CONSELHO NACIONAL DE JUSTIÇA. Corregedoria normatiza troca de nome e gênero em cartório. CNJ, 2018. Disponível em:<http://www.cnj.jus.br/noticias/cnj/87092-corregedoria-normatizatroca-de-nome-e-genero-em-cartorio>. Acesso em: 10 jul. 2018;

GORISCH, Patrícia. STF reconhece às pessoas trans o direito de alteração no registro civil sem necessidade de cirurgia de transgenitalização. Instituto Brasileiro de Direito de Família - IBDFAM, mar. $2018 . \quad$ Disponível em:<http://www.ibdfam.org.br/noticias/6548/STF+reconhece+\%C3\%A0s+pessoas+trans+o+direit o+de+altera\%C3\%A7\%C3\%A3o+no+registro+civil+sem+necessidade+de+cirurgia+de+transgenitaliz a\%C3\%A7\%C3\%A3o>. Acesso em: 09 jul. 2018;

KUMPEL, Vitor Frederico; VIANA, Giselle Menezes. Mudança de nome do Transexual: O Registro Civil mais uma vez sob os holofotes do STF. Revista ARPEN/SP, São Paulo, n. 181, p. 2728,mar./abr. 2018;

MORAES, Alexandre de. Direito Constitucional. 32a . Ed. São Paulo: Atlas, 2016;

PRESSE, F. Trasngênero: fatos, mitos e direitos.G1 - Bem Estar, 2016. Disponível em:<http://g1.globo.com/bemestar/noticia/2016/06/transgenero-fatos-mitos-e-direitos.html>. Acesso em: 11jul. 2018; 
SENKEVICS, A. As armadilhas do "lugar de fala" na política contemporânea.Ensaios de Gênero, 2017. Disponível em:< https://ensaiosdegenero.wordpress.com/>. Acesso em: 17jul. 2018;

SOUZA, Carlos Magno Alves de. A Decisão do STF em reconhecer aos transgêneros o direito à alteração de prenome e sexo diretamente no Registro Civil.Revista ARPEN/SP, São Paulo, n. 181, p. 24-26,mar./abr. 2018.

TRANSGÊNEROS ganham o direito de mudar de nome e gênero sem ordem judicial.ARPEN/SP, São Paulo, n. 181, p. 12 e 17, mar./abr. 2018. 